\title{
SÁBADOS DIVERTIDOS: UMA EXPERIÊNCIA DE EXTENSÃO NO CENTRO UNIVERSITÁRIO DE BRUSQUE UNIFEBE
}

\author{
ENTERTAINING SATURDAYS: \\ AN EXTENSION EXPERIENCE \\ AT THE UNIVERSITY OF \\ BRUSQUE UNIFEBE
}

RESUMO

O Projeto Sábados Divertidos é promovido, em Santa Catarina, pelo Centro Universitário de Brusque UNIFEBE e busca incentivar atividades recreativas com crianças do ensino fundamental das escolas municipais de Brusque e nos municípios vizinhos. $O$ sentido é atuar de forma motivadora e envolvê-las em atividades de Lazer num momento de integração, diversão, solidariedade em diversas atividades. A preocupação deste projeto se dá quanto à inclusão na forma mais ampla que este termo possa suscitar, a "Inclusão Social", que, por sua vez, visa integrar crianças de comunidades carentes que, em grande parte de seu tempo, não possuem acesso a lugares específicos para atividades de lazer.

Palavras-chave: UNIFEBE. Brusque. Extensão Universitária. Relato de Experiência.

\section{ABSTRACT}

The Project "Entertaining Saturdays" is promoted in Santa Catarina by the University Center of Brusque UNIFEBE and aims to encourage recreational activities with children from municipal elementary schools in Brusque and neighboring towns. The objective of the project is to act in a motivating way to engage the children in leisure activities in a time of integration, fun and solidarity in various activities. The concern of

\footnotetext{
1 Professor do Centro Universitário de Brusque (UNIFEBE). Aluno do curso de Mestrado em Administração da Universidade do Vale do Itajaí (UNIVALI). E-mail: claudemir.marcolla@hotmail.com

2 Professor e pesquisador do Centro Universitário de Brusque (UNIFEBE) e da Universidade Alto Vale do Rio do Peixe (UNIARP) Brasil. Doutorado em Sociologia Política pela Universidade Federal de Santa Catarina (UFSC). E-mail: prof.evesilva@gmail.com 3 Professor e pesquisador do Centro Universitário de Brusque (UNIFEBE) e da Universidade Alto Vale do Rio do Peixe (UNIARP)، Brasil. Doutor em Teologia pela Escola Superior de Teologia, (EST), Brasil. E-mail: baadejoel@gmail.com.

4 Professora e Coordenadora de Relações Internacionais do Centro Universitário de Brusque (UNIFEBE). Especialista em Língua Inglesa pelo Centro Universitário de Jaraguá do Sul. E-mail: internacional@unifebe.edu.br

5 Pró-Reitora de Pós-Graduação, Pesquisa e Extensão do Centro Universitário de Brusque (UNIFEBE). Mestrado em Educação pela Universidade do Vale do Itajaí (UNIVALI). E-mail: helo@unifebe.edu.br.
} 
this project is related to the inclusion in the broadest sense of the term, that is "Social Inclusion", and its goal is to integrate children from underprivileged communities that in most of their free time do not have access to specific places designed to leisure activities.

Keywords: UNIFEBE. Brusque. University Extension. Experience Report.

\section{Introduçáo}

A globalização faz parte do contexto histórico-cultural no século XXI, apresentando aspectos positivos e negativos. Como aspecto positivo, destaca-se a industrialização, que, a priori, deveria aumentar o tempo livre das pessoas para a prática do lazer. Quanto ao aspecto negativo, o que mais preocupa é que o ser humano está cada vez mais sedentário, se ocupa da mídia eletrônica (televisão, internet etc.) para, de uma maneira econômica, junto da família, satisfazer as suas necessidades de lazer.

A palavra lazer não tem um significado muito claro. Isso faz com que o sentido que exprime a ideia de lazer caminhe para um significado de ausência ou afrouxamento de diferentes formas de restriçóes ou de dependência, ausência de regras, obrigaçóes, de repressão ou de censura. O francês Dumaziedier (apud ANDRADE, 2001, p. 42) preconiza o lazer como o

[...] conjunto de ocupaçóes às quais o indivíduo pode se entregar de livre vontade, seja para repousar, seja para se divertir, se recrear e se entreter, ou, ainda, para desenvolver sua informação ou formação desinteressada, sua participação social e voluntária ou sua livre capacidade criadora, após se livrar das obrigaçôes profissionais, familiares e sociais.

Brusque é uma cidade que conta com poucas oportunidades de lazer, principalmente nos finais de semana. A UNIFEBE, ao perceber esta necessidade da comunidade e, por ter como finalidade - como destaca na sua missão - o compromisso com a humanização, está disposta a oferecer atividades de lazer através dos cursos de graduação da Instituição. Nesse sentido, propóe desenvolver mensalmente "Sábados Divertidos", em que acadêmicos são integrados na participação de projetos de extensão na comunidade.

Acredita-se que a UNIFEBE está disposta a aproximar-se cada vez mais da comunidade, especialmente para contribuir efetivamente com a sua missão, se projetando como uma Instituição de Ensino, Pesquisa e Extensão.

A Constituição de 1998, no seu artigo 6º na Emenda Constitucional no 26 de 2000, destaca que "são direitos sociais a educação, a saúde, o trabalho, a moradia, o lazer, a segurança, a previdência social, a proteção à maternidade e à infância, a assistência aos desamparados, na forma desta constituição" (BRASIL, 2000, p.30).

Sabe-se que a maioria dos brasileiros não tem acesso pleno a esses direitos fundamentais que estão previstos em lei, e muitos daqueles que os têm pagam, individualmente, clubes, academias, cinemas, teatros etc. Assim, lazer pode soar como artigo de luxo para a enorme parcela da populaçáo, o que é triste, sendo talvez estes indivíduos os que mais precisam de apoio, para, de fato, usufruírem da sua condição de cidadão.

O lazer consiste em um elemento indispensável para a saúde mental da pessoa, principalmente no momento em que as pressóes no trabalho e a insegurança social aumentam. Os centros comunitários para prática de esportes e lazer são construídos, a priori, no centro das cidades, onde um grande número de pessoas fica com tempo ocioso nos finais de semana. Nos bairros da cidade de Brusque e das cidades próximas, existem poucos locais para a prática de lazer. Os que existem são frequentados por uma pequena parcela de sócios, sem mencionar os poucos atrativos que possuem.

Entende-se por lazer o tempo livre ocupado para fazer algo que propicia prazer ao ser humano. 
Nessa perspectiva, propóe-se como uma alternativa relativamente econômica atividades de lazer em escolas públicas de Brusque e região, nas quais as crianças possam caminhar, brincar, jogar e se divertir.

A grande diferença existente entre a recreaçáo e o lazer reside na escolha das atividades exercidas. Enquanto no lazer o indivíduo possui graus de liberdade para sua escolha, na recreação as atividades são naturalmente impulsionadas por motivos interiores, seja de aspectos físico, psicológico ou social.

Tanto o lazer como a recreação têmuma dupla finalidade: satisfazer a ociosidade e a utilizaçáo do tempo livre conquistado pela sociedade contemporânea. Este paradigma permite fazer consideraçóes relacionadas ao lazer: o desejo de poder compensar a ociosidade do tempo livre, a massificaçáo destas atividades, grande parte da recreaçáo e suainfraestrutura podem servir de suporte para o lazer, constituindo uma necessidade contemporânea.

Por mais estranho que pareça falar em lazer, uma vez que esta atividade é praticada pela sociedade, deve-se considerar alguns dos elementos abordados. Inegavelmente, o homem sonha com a Era dos Lazeres, fato que aparentemente está distante, principalmente devido ao consumo de tempo solicitado pelas atividades de subsídio às tarefas laborais.

De acordo com Gomes (2004), a produçáo científica sobre o lazer iniciou-se no Brasil por volta da década de 1970, com o desenvolvimento de pesquisas e projetos específicos. Estudiosos como Domênico De Masi e Paul Singer, em suas publicaçóes, sob a ótica do futuro do trabalho, globalização e desemprego, discutem diagnósticos e alternativas das perspectivas futuras.

\section{Um pouco da história de Santa Catarina}

É impreterível salientar que é ampla a produção historiográfica existente sobre o processo de formação do estado de Santa Catarina. Pode-se destacar, em especial, os trabalhos de Alcides Goularti Filho, no livro Formação Econômica de Santa Catarina, e de CécileHélène Jeanne Raud, no livro Indústria, Território e Meio Ambiente no Brasil, para melhor entendimento da história geral e econômica do Estado de Santa Catarina.

Santa Catarina apareceu, como regiáo geográfica, somente em 1529, no mapamúndi de Diego Ribeiro e também nas Cartas dos Navegadores do Século XVI. Com relação ao nome, primeiramente foi "Ilha de Santa Catarina", onde fica hoje localizada a capital do Estado, Florianópolis.

Na direção indicada pelo INEP (2006), Santa Catarina começou sua história, no século XVI, com a fundaçẫo das primeiras colônias europeias, formadas por portugueses vindos de São Vicente. Já no século XVII, houve a ocupação do litoral

[...] com os vicentistas, religiosos vindos da região de Sáo Paulo, continuando no século XVIII com os açorianos, que fundaram São Francisco do Sul (1645), Desterro (hoje Florianópolis, em 1651) e Laguna (1676). Da mesma maneira, o governo português promoveu, entre 1748 e 1756, a vinda de alguns milhares de casais açorianos. Eles chegavam na Ilha de Santa Catarina, estabelecendo-se lá ou no Litoral. Essa população, constituída basicamente de pequenos agricultores e pescadores, dedicava-se à agricultura de subsistência, mas também atividades mercantis, como a pesca da baleia, com a produção de azeite, e a fabricação de farinha de mandioca (RAUD, 1999, p.85). 
O estado de Santa Catarina fica no Sul do Brasil, no centro geográfico das regióes de maior desempenho econômico do país, Sul e Sudeste, e em uma posição estratégica no Mercosul. Fica situado na região Oeste, na fronteira com a Argentina. Florianópolis, a capital, está a $1.850 \mathrm{~km}$ de Buenos Aires, $705 \mathrm{~km}$ de São Paulo, $1.144 \mathrm{~km}$ do Rio de Janeiro e $1.673 \mathrm{~km}$ de Brasília. O estado catarinense situa-se entre os paralelos $25^{\circ} 57^{\prime} 41^{\prime \prime}$ e 29023'55” de latitude Sul e entre os meridianos 48¹9'37' e 53050'00" de longitude Oeste. (GOVERNO DO ESTADO DE SANTA CATARINA, 2009).

$\mathrm{Na}$ iminência da queda das barreiras alfandegárias do Mercosul, Santa Catarina é a rota da integração com as naçóes vizinhas. $\mathrm{O}$ maior parceiro comercial de Santa Catarina continua sendo os Estados Unidos, mas a Argentina acaba de superar a Alemanha, assumindo o segundo lugar. Eis aí o indício de um novo dinamismo que inaugura as ampliadas fronteiras dos negócios do Cone Sul ${ }^{6}$.

A diversidade das atividades industriais e a equilibrada distribuição geográfica dos polos produtivos são as principais características do chamado modelo econômico catarinense. Além da boa distribuição fundiária, como propriedades rurais de área média, ao redor de 20 hectares, predomina a desconcentração populacional.

Em termos globais, Santa Catarina é o vigésimo estado em área, com 95 mil quilômetros quadrados, o equivalente a $1,12 \%$ do território nacional, tendo uma população estimada, em 2009, de 6.118.743 de habitantes em 293 municípios.

Além do exposto, o Estado está dividido em oito regióes: Litoral, Nordeste, Vale do Itajaí, Planalto Norte, Planalto Serrano, Sul, Meio-Oeste e Oeste.

No que se refere à atividade econômica do estado de Santa Catarina, é caracterizada pela divisão em complexos: Agroindustrial (Oeste); Eletro-Metal-Mecânico (Norte); Madeireiro (Planalto); Têxtil (Vale do Itajaí); Mineral (Sul); Tecnológico (Grande Florianópolis); Turístico (praticamente todo o Estado); e, Pesqueiro.

A saber, o complexo têxtil desenvolveu e transformou a região do Vale do Itajaí num dos maiores fabricantes nacionais de malhas, artigos de cama, mesa e banho, sem que o estado produza um só quilo de algodão. Da mesma forma, o complexo eletrometal-mecânico e plástico, no nordeste catarinense, que desponta ainda como grande fabricante de motores elétricos, compressores para refrigeração, fundidos de ferro e tubos de PVC, embora Santa Catarina não disponha de um polo petroquímico ou siderúrgico.

O complexo têxtil, segundo levantamento do departamento de apoio industrial da Federação das Indústrias do Estado de Santa Catarina (2010), compreende 12,6 mil empresas de vestuário, calçados e artefatos de tecidos e responde por $25 \%$ do Valor de Transformação Industrial (VTI). Em 1999, empregou diretamente mais de 90 mil pessoas, das quais mais de 50 mil em quase 2 mil estabelecimentos no Vale do Itajaí, e o setor espera uma retomada da produçáo, em virtude da estabilidade cambial e da política dos governos estaduais e federal de incentivo às exportaçóes.

O estado de Santa Catarina apresenta, ainda, sérios problemas de desigualdade social e ambiental, como as enchentes. Entretanto, o governo e as "elites" locais sempre demonstraram preocupação com esse desequilíbrio.

Com o intuito de diminuir esse desequilíbrio e aproximar as regióes do estado, foram criadas 36 Secretarias de Desenvolvimento Regional, que têm como foco descentralizar as açóes do governo e adotar políticas de desenvolvimento regional sustentável. Náo obstante, como foi dito anteriormente, os governantes que assumem o poder demonstram 
continuamente preocupação com a diminuição da desigualdade social. Nesse sentido, independentemente de quem assume o poder, partido ou pessoa, são colocadas como pauta açôes de fortalecimento do setor educacional.

No que tange à educação superior em Santa Catarina, vale ressaltar que, até a expansão das instituiçóes de educaçáo superior privadas, no período do governo Fernando Henrique Cardoso, o sistema ACAFE era única entidade representativa da educação superior catarinense. Esse sistema foi criado em 1974, quando os

[...] presidentes das fundaçôes criadas por lei municipal e da fundação criada pelo Estado constituíram a ACAFE - Associação Catarinense das Fundaçôes Educacionais, entidade sem fins lucrativos, com a missão de promover a integração dos esforços de consolidação das instituiçôes de ensino superior por elas mantidas, de executar atividades de suporte técnico-operacional e de representá-las junto aos órgãos dos Governos Estadual e Federal (ACAFE, 2010).

Até o ano de 1989, existiam duas instituiçóes públicas (UFSC e UDESC), as instituições municipais filiadas à ACAFE e apenas uma Instituição particular (Associação Catarinense de Ensino (ACE), de Joinville).

Em 2014, fazem parte do sistema ACAFE as seguintes instituiçóes: Universidade Regional de Blumenau (FURB); Centro Universitário Barriga Verde (UNIBAVE); Centro Universitário de Jaraguá do Sul (UNERJ); Universidade do Extremo Sul Catarinense (UNESC); Universidade do Vale do Itajaí (UNIVALI); Universidade do Estado de Santa Catarina (UDESC); Universidade do Oeste de Santa Catarina (UNOESC); Centro Universitário Municipal de São José (USJ); Centro Universitário de Brusque (UNIFEBE); Centro Universitário para o Desenvolvimento do Alto Vale do Itajaí (UNIDAVI); Universidade do Planalto Catarinense (UNIPLAC); Universidade da Região de Joinville (UNIVILLE); Universidade do Sul de Santa Catarina (UNISUL); Universidade do Contestado (UnC); Universidade Comunitária da Região de Chapecó (UNOCHAPECÓ); e Universidade do Alto Vale do Rio do Peixe (UNIARP).

\section{Setor têxtil no Vale do Itajaí}

O setor têxtil catarinense está basicamente localizado no Vale do Itajaí ${ }^{7}$, especialmente nas cidades de Brusque, Guabiruba, Blumenau, Indaial, Gaspar e Pomerode. No Norte, nas cidades de Jaraguá do Sul e Joinville; e um pouco no Sul, especialmente em Criciúma. Os municípios de Blumenau, Brusque, Joinville e Jaraguá do Sul concentram 50 mil trabalhadores, perfazendo quase a metade total do Estado.

Uma das cidades pioneiras, a então colônia Blumenau ${ }^{8}$, dedicou-se em grande parte à produção de produtos agrícolas, alimento, bebida, madeira e tijolos, no período de 1850 até 1880 . Somente após 1875 é que a indústria têxtil deu os seus primeiros passos com a chegada de novos imigrantes, que vieram da Saxônia, região industrial da Alemanha recém-unificada. Em 1880, é criada a empresa Gebrüder Hering, fundada pelos irmãos Hermann Hering e Bruno Hering (hoje, Cia. Hering). Outra empresa surge em 1882, com o Sr. Johann Karsten, que ao comprar seis teares alemães, abriu uma pequena

7 Há vários estudos sobre a origem da indústria no Vale do Itajaí, ver: Mamigonian (1965), Singer (1977), Castro (1980), Seyferth (1973), Colombi (1979), Hillesheim (1979), Hering (1987) e Vidor (1995).

8 Fundada em 2 de setembro de 1850, com a chegada de 17 imigrantes da Alemanha. 
tecelagem: a Karsten (hoje, Karsten S.A.). Logo após em 1884, é aberta a empresa Garcia (GOULARTI FILHO, 2002; MAMIGONIAN, 1965).

De 1880 até 1945 , o setor têxtil catarinense caminhou lentamente, mas a partir desse último, ano até 1962, o setor acaba se consolidando, com grandes e médias empresas que abrangiam todo o país. É mister apontar como cidades que foram destaque nessa expansão: Blumenau, através das empresas Cremer, Sulfabril, Teka, Hering, Haco Etiquetas e Garcia (empregando 1.400 funcionários, sendo a maior fábrica de Santa Catarina, ao lado da Hering); e, Brusque, através das empresas Schlösser e Renaux.

A partir dos anos 1950, o Vale do Itajaí já merecia destaque pela sua forte expansão e diversificação, passando pela fiação, tecelagem, malharia, beneficiamento e confecção de vestuário. Com relação à Blumenau, Mamigonian (apud GOULARTI FILHO, 2002, p.154) faz o seguinte relato:

Os quatro estabelecimentos têxteis de mais de 500 operários têm além da tecelagem ou uma malharia, suas próprias fiaçóes e tinturarias, e outros anexos como marcenarias e oficinas mecânicas capazes de construir os teares de que necessitam. Kuehnrich (atual Teka), com 319 operários, pode ser assimilada a este grupo. Os outros estabelecimentos têxteis que têm entre 100 e 500 operários, como Haco, Sulfabril, Malharia Blumenau (Mafisa) e Karsten, não possuem fiaçóes, mas a Malharia Blumenau recebia antigamente o fio de algodão da fiação Hering, do mesmo grupo familiar; Sulfabril é muito recente e Haco tem náo somente sua tecelagem e sua tinturaria, mas fabrica também, na sua oficina mecânica, seus próprios teares e, na sua marcenaria, suas próprias lançadeiras.

Em 1958, as cidades de Blumenau (66,6\% mão de obra) e Brusque (84,5\% mão de obra) destacavam-se como polo da indústria têxtil, com inúmeras malharias e tecelagens, de pequeno, médio e grande porte, tomando características de oligopólio, nos anos 1960, perdendo apenas para São Paulo e Guanabara.

O setor têxtil é muito sensível às mudanças econômicas do mercado. Nesse sentido, os anos 1970 foram marcados por uma considerável expansão do setor, devido ao "milagre econômico" da época e à expansão promovida pelo II PND (Plano Nacional de Desenvolvimento). Em 1976, a Hering foi novamente beneficiada pela Sudene e expandiu ainda mais a sua produção. A empresa Sulfabril, que também recebeu recursos da Sudene, abriu, em 1979, uma unidade em Natal, adquirindo, em Joinville, uma fiação, e construindo unidades em Apiúna e Gaspar. Outras empresas, como a Teka (aumentou sua capacidade produtiva para outros Estados), Cremer (ampliou a oferta de novos produtos) e Schlösser (modernizou seu parque fabril) fizeram investimentos e ampliaçóes (FIGUEIRA, 1980; GOULARTI FILHO, 2002; KUEHNRICH, 1995; SCHLÖSSER, 1986; CREMER, 1985).

$\mathrm{Na}$ década de 1980, o setor já deu alguns sinais de instabilidade. Do período de 1981 até 1983, o setor foi duramente afetado, voltando a se recuperar nos anos seguintes, mantendo-se estável até o final de 1989, porém num ritmo inferior ao período passado. Nessa década, também o número de oferta de empregos apresentava aumento significativo: dos 41.000 empregos diretos aumentou para 58.700 em 1989, o que representou um aumento de 43,2\%. Segundo Moser (apud GOULARTI FILHO, 2002, p.287), "a oferta aumenta devido à abertura de novas plantas das maiores empresas em outros municípios, em busca de mão-de-obra mais dócil e da descentralização da produção verticalizada”.

É mister salientar que a economia do Vale do Itajaí está fortemente apoiada na produção têxtil, fato que compromete a economia de algumas cidades dependentes desse 
setor. Conforme se pode observar na Tabela 1, há muita instabilidade no emprego têxtil, porque é um setor que oscila bastante, positiva ou negativamente, devido às decisóes de caráter macroeconômico e microeconômico, como por exemplo, a política cambial, a política monetária e a política industrial.

Enfim, o setor têxtil catarinense passou por várias fases, com destaque para os anos 1950 e 1960, que foram de crescimento para o setor, seguidos pelos anos 1970, de expansão para o Nordeste, Paraná e São Paulo. Os anos 1980 foram marcados pela diversificação e ampliação para o mercado externo, e os anos 1990, de queda no setor.

Houve um aumento das exportaçóes e da produçáo, ocorrendo apenas um leve declínio no número de empregos, especialmente nos anos 1995, 1996 e 1997, com recuperaçáo em 2000, ou seja, há instabilidade, mas há crescimento.

Em síntese: o setor têxtil catarinense passou por transformações profundas na década de 1990, que alteraram significativamente os processos de produção, de administração da força de trabalho e de planejamento das empresas. Destarte, ocorreram as terceirizaçóes, principalmente de costura e confecção, com o intuito de redução de custos para as empresas, pagando-se salários ainda menores para os trabalhadores, o que contribuiu para o enfraquecimento da organizaçáo sindical do setor (assunto a ser discutido no próximo item).

As empresas catarinenses voltaram a ter uma melhora somente a partir de janeiro de 1999, com a desvalorizaçáo do câmbio, que, por um lado, dificultou as importaçóes e, por outro, aumentou as exportaçóes. Segundo a ABIT (Associação Brasileira da Indústria Têxtil e de Confecção) $)^{9}$, o setor têxtil cresceu 6\% em 2001 e obteve um superávit comercial de US\$ 300 milhóes, em 2002.

O estado de Santa Catarina, em 2006, foi considerado o quarto melhor do país no índice de desenvolvimento, perdendo apenas para São Paulo, Rio de Janeiro e Paraná, pelo índice Firjan de Desenvolvimento Municipal (IFDM) (FIRJAN, 2009), efetuado pela Federação das Indústrias do Estado do Rio de Janeiro (FIRJAN), que leva igualmente em conta as três áreas de desenvolvimento humano: Emprego \& Renda, Educação e Saúde. $\mathrm{Na}$ área educacional, que motivou a realização desta análise, Santa Catarina encontra-se em terceiro lugar no país, fato que corrobora a importância dessa área para o mercado.

\section{Comprometimento com a comunidade}

A Fundaçáo Educacional de Brusque - FEBE, instituída pela Lei Municipal $\mathrm{n}^{\circ}$. 527/73, de 15 de janeiro de 1973, é uma entidade pública dotada de personalidade jurídica de direito privado, sem fins lucrativos, de caráter comunitário, tendo como seu idealizador o professor Padre Orlando Maria Murphy, que foi seu primeiro presidente.

A regulamentação para funcionamento da UNIFEBE é o Decreto Municipal no. 646/75, de 08 de agosto de 1975 e, atualmente, a Fundaçáo é regida por Estatuto aprovado pelo Ministério Público (Curador das Fundaçóes), registrado no Cartório de Títulos e Documentos, Pessoas Jurídicas e Outros Papéis da Comarca de Brusque/SC, sob o no. 000622, Als. 020, no livro A-5, em 18 de fevereiro de 1999 (PPI, 2008).

A FEBE é a mantenedora do Centro Universitário de Brusque - UNIFEBE, credenciado pelo Governador do Estado de Santa Catarina, através do Decreto Estadual 
no. 647/03, de 29 de agosto de 2003. Por conseguinte, a Fundação Educacional de Brusque - FEBE é administrada pelo Conselho Curador (CC), pelo Conselho Administrativo (CA) e por sua Presidência.

Destaca-se que a UNIFEBE busca formar cidadáos éticos, conscientes dos problemas de sua época e comprometidos com a qualidade de vida na sociedade. O princípio que norteia o trabalho da Instituição é promover o Ensino Superior de qualidade, a partir de um projeto educativo inovador que responda aos desafios atuais.

Por ser uma Instituiçáo comunitária, sua missão se destaca na área humanística, conforme preconiza sua missáo, que é "Atuar no Ensino Superior pautado em uma perspectiva humanista e comprometido com o desenvolvimento que promova a qualidade de vida na sociedade" (UNIFEBE, 2014). Já a visão é "Ser referência em Educaçáo Superior atuando como protagonista na produçáo do conhecimento voltado para o bem comum" (UNIFEBE, 2014).

O Estatuto da UNIFEBE determina que sua Administração Superior seja exercida pelo Conselho Universitário (Consuni), pela Reitoria, pela Pró-Reitoria de Ensino de Graduação, pela Pró-Reitoria de Pós-Graduação, Pesquisa e Extensão e pela Pró-Reitoria de Administração.

A UNIFEBE, comprometida com sua missão, busca articular a extensão universitária associada ao ensino e à iniciação científica. O Plano Nacional de Extensão Universitária destaca:

Extensão Universitária é o processo educativo, cultural e científico que articula o Ensino e a Pesquisa de forma indissociável e viabiliza a relação transformadora entre Universidade e Sociedade. A Extensão é uma via de mão-dupla, com trânsito assegurado à comunidade acadêmica, que encontrará, na sociedade, a oportunidade de elaboração da práxis de um conhecimento acadêmico. No retorno à Universidade, docentes e discentes trarão um aprendizado que, submetido à reflexão teórica, será acrescido àquele conhecimento. (BRASIL, 2001, p. 5).

Assim, as açóes de iniciação científica e extensão assumem papel acadêmico relevante, uma vez que qualificam o ensino de graduação e, ainda, por meio do desenvolvimento e da socializaçáo do conhecimento adquirido, aliados às necessidades da comunidade local e regional, promovem a melhoria da qualidade de vida das pessoas.

A Pró-Reitoria de Pós-Graduação, Pesquisa e Extensão (Proppex) propóe, coordena, acompanha e avalia as atividades relacionadas à política de Pós-Graduação, Pesquisa e Extensáo da UNIFEBE, implementadas com o compromisso de contribuir para a produção, sistematização e disseminação do conhecimento aqui construído, de forma ativa e articulada com o ensino e a sociedade.

Mesquita (1997) destaca que existem mais de 19 conceitos diferentes de extensão, e os divide em cinco categorias: Oferta de Cursos; Prestaçấo de Serviços; Atividade Complementar ao ensino e à pesquisa; Compensaçáo para suprir as falhas do ensino regular e instrumento político-social. Na UNIFEBE, a extensão é concebida como um espaço de troca, em que a Instituição intervém e é redimensionada pelas questôes levantadas pela comunidade. Essas questóes podem apontar novas diretrizes ao ensino e questôes atuais para o desenvolvimento de novas açóes de iniciaçáo científica.

Rosa (2010) destaca que a prática da extensão universitária exige uma participação e um processo crítico-reflexivo de todos os atores sociais. Deste modo, a Instituição busca constantemente ampliar as açôes de iniciação científica e extensão, pois entende que é a 
partir do ensino de qualidade,vinculado às açóes de extensão e aos novos questionamentos emergentes das atividades de iniciação científica, que é possível contribuir para o desenvolvimento e a melhoria da qualidade de vida da comunidade.

Toda atividade de extensáo está regulamentada pelo Regulamento das Açóes de Extensão foi aprovado pelo Conselho Universitário em 29 de setembro de 2009 e, desde então,as açôes de extensão se intensificaram na Instituição.

\section{Cursos de extensão e nivelamento}

A UNIFEBE foi criada pelo Poder Público Municipal, mas é mantida com recursos financeiros preponderantemente da comunidade, e tem como foco de atendimento o fortalecimento das demandas da comunidade local e regional onde está inserida. Desse modo, sua intervençáo na comunidade tem corroborado de forma significativa seu relevante papel de protagonista do desenvolvimento local e regional, contribuindo para o fortalecimento da economia, dos valores sociais do trabalho e da livre iniciativa bem como de valores humanos e éticos.

O Centro Universitário de Brusque - UNIFEBE tem como um de seus objetivos institucionais compartilhar o conhecimento desenvolvido na Instituiçáo com a comunidade local e regional. A produção do conhecimento é estimulada por meio de atividades acadêmicas de ensino, iniciaçấo científica e extensão, com o intuito de colocar seus resultados a serviço da sociedade, solidificando, assim, sua essência de Instituição de Educação Superior Comunitária. Assim, o conhecimento construído na UNIFEBE por meio de seus cursos de graduaçáo e das mais diversas atividades acadêmicas é desenvolvido visando beneficiar a comunidade de sua área de abrangência.

Os cursos de extensáo e nivelamento visam, ainda, atender os desafios presentes na sociedade atual, promovendo a reflexão, o debate e o olhar crítico sobre a sociedade que nos cerca; proporcionar ao participante atualização técnico-profissional e pessoal, ressaltando o caráter de formaçáo integral da pessoa e, assim, fazendo-a parceira e inserindo-a como corresponsável pela construçấo de uma sociedade mais equilibrada e justa; formar não apenas eficientes técnicos, mas indivíduos socialmente responsáveis; fomentar nas pessoas o pensamento crítico, para que elas possam contribuir de alguma forma por meio de sua atuação participativa na comunidade, a transformação das estruturas econômicas, sociais e políticas.

Atualmente, são oferecidos cursos de nivelamento em Língua Portuguesa e Matemática e cursos de extensão de Libras, Gestáo de Pessoas, Contabilidade, Economia, Xadrez, Desenho Técnico, Argumentaçáo Jurídica, Corte e Costura, Fotografia, Compras, Direção Defensiva, Google Drive, Libre Office, Nanotecnologia no desenvolvimento de cosméticos e Oratória.

\section{Metodologia do projeto}

O Projeto Sábados Divertidos promove atividades recreativas com crianças do ensino fundamental nas escolas municipais de Brusque e nos municípios vizinhos durante os sábados, das $8 \mathrm{~h}$ às $12 \mathrm{~h}$, durante 5 (cinco) sábados por semestre. O sentido é atuar de 
forma motivadora a envolvê-los nas atividades de Lazer num momento de integraçáo, diversão, solidariedade nas diversas atividades, como: jogos de mesa, cama elástica, arte com balóes, pintura facial, pintura de cabelo, tênis de mesa, jogos gigantes, entre outros.

O Projeto surgiu no ano de 2012, foi contemplado com o Edital do Conselho Municipal dos Direitos da Criança e Adolescente (CMDCA) e recebeu recursos do Fundo da Infância e Adolescência (FIA). Em 21 de agosto de 2013, já sem o recurso municipal para manter o projeto, a UNIFEBE, por intermédio do parecer 047/13 do Conselho Universitário (CONSUNI), aprovou o Projeto Permanente de Extensão Sábados Divertidos. A partir desta data, o Projeto foi mantido com recursos próprios.

Os participantes são os alunos dos cursos de graduação da UNIFEBE beneficiados com a bolsa de estudos do artigo 170, advindo do Governo do Estado de Santa Catarina, e da bolsa de estudos Institucional da UNIFEBE. Ao se candidatar para a bolsa de estudos de alunos carentes, o aluno deve escolher um dos projetos sociais que a IES disponibiliza, dentre eles o Sábados Divertidos.

Ao sair o resultado dos bolsistas contemplados, eles são informados pelo Serviço de Orientaçáo ao Estudante (SOAE) da data do primeiro encontro, que trata sobre os procedimentos dos Sábados Divertidos. Anteriormente, o setor de Extensão agenda previamente com Escolas e Centros de Educaçáo Infantil do Município de Brusque-SC e entornos a execução do Projeto. A seleçáo das escolas é feita por intermédio de um e-mail, com as datas disponíveis, enviado a todas as escolas, e a escolha é feita por ordem de resposta a este e-mail.

Após a escolha dos locais, cabe ao setor de extensão, ainda: (1) a solicitaçáo de compra dos materiais à Pró-Reitoria de Administraçáo; (2) reuniáo com os bolsistas para entrega do cronograma, coletes, distribuição das atividades individuais, orientaçóes gerais e apresentaçáo do coordenador das atividades (professor de Educaçáo Física da IES); (3) deslocamento dos materiais e execução do projeto nas escolas; e, (4) encontro com os envolvidos para avaliar o Projeto.

O Projeto tem como objetivo geral promover atividades de lazer, disponibilizando a significação dos conhecimentos acadêmicos para os alunos envolvidos na efetiva ação social, vinculando, assim, a Unifebe como agente promotora de atividades de pesquisa e de extensão junto à comunidade de Brusque.

Os objetivos específicos do Projeto são:

a) Estabelecer maior integração entre a Unifebe e a comunidade;

b) Promover atividades à comunidade de Brusque e regiáo, com a participação dos acadêmicos contemplados com bolsa estadual do Artigo 170 e voluntários dos diversos Cursos de Graduação da Unifebe;

c) Proporcionar aos participantes atividades de lazer, com o intuito de desenvolver e estimular sua prática;

d) Enfatizar a importância do lazer e da prática de atividades para o crescimento saudável da criança.

Torna-se imprescindível a integração da UNIFEBE com a comunidade nas diversas atividades propostas, o que possibilitou o despertar do espírito solidário, que, por certo, tem reflexos positivos no cotidiano social. Cabe ressaltar que este Projeto não tem por finalidade o espírito competitivo; neste contexto, não há vencedores nem perdedores, mas indivíduos felizes em viver plenamente momentos harmoniosos e divertidos. 
O Lazer é uma atividade que, quando bem planejada, orientada e executada, desenvolve-se de forma normal e se torna permanente na vida humana. Seus objetivos visam: maior interação do indivíduo no seu meio social; melhoria do nível intelectual de cada participante; afirmaçáo do indivíduo e reconhecimento de suas preferências e habilidades.

Para mensurar quantitativamente o impacto do Projeto na comunidade, é de responsabilidade do coordenador quantificar os participantes em cada encontro. No primeiro semestre de 2013, o Projeto obteve a participaçáo de 14 bolsistas, alcançando pouco mais de 600 crianças nas 5 escolas participantes. Já no segundo semestre de 2013, a participaçáo foi de 13 bolsistas em 5 escolas de Brusque e Regiáo, alcançando 475 crianças.

No primeiro semestre de 2014, houve a participaçáo de 14 bolsistas e mais 3 acadêmicos voluntários, alcançando 640 crianças de 5 escolas do município de Brusque. Para o segundo semestre de 2014, o Projeto foi desenvolvido em 4 escolas de Brusque e participou de um evento na cidade de Canelinha - SC, voltado para crianças carentes. Mais de 800 crianças foram atendidas. O Centro Universitário de Brusque - UNIFEBE adquiriu mais uma cama elástica de porte médio para atender melhor estas comunidades que tanto precisam de projetos deste cunho.

De maneira informal, em conversas com pais, professores e diretores das escolas, ouve-se a necessidade de mais atividades recreativas no município, principalmente em bairros mais distantes do centro. Nos alunos bolsistas, percebe-se a evolução com o passar dos encontros, pois eles iniciam no projeto tímidos e individualistas e encerram interagindo com os colegas de Projeto e com as crianças, como se despertasse "um espírito solidário" em todos os participantes.

\section{Consideraçóes finais e sugestóes}

Em vista dos resultados obtidos e ao se avaliar quantitativa e qualitativamente os resultados do Projeto nos últimos dois anos, pode-se afirmar que eles estão sendo alcançados. Com efeito, destaca-se o crescente envolvimento e a evoluçáo dos acadêmicos no decorrer das atividades.

Levando em consideração as condições regionais em que a UNIFEBE está localizada, ela se adapta à realidade da cidade de Brusque e regiấo do Vale do Itajaí, em Santa Catarina. Entretanto, como Instituição Comunitária, atua diretamente na comunidade local e regional, tendo a responsabilidade de formar cidadáos cônscios de seus direitos e deveres. Ademais, isso ocorre por intermédio de açôes e projetos que possam, de alguma maneira, beneficiar a sociedade.

Propositadamente,destaca-se a evoluçáo dos setores têxtil e metalúrgico na fundamentação teórica, devido à empregabilidade que oferecem na região, sendo os trabalhadores e suas famílias os maiores beneficiários com o Projeto Sábados Divertidos.

Portanto, cabe à Instituição o compromisso de continuar aplicando seus recursos neste projeto que tanto favorece a comunidade acadêmica e local da Regiáo do Vale do Itajaí Mirim. Para tanto, percebe-se que a necessidade de voluntários aumenta cada vez mais, visto que se percebe aumento gradativo de solicitaçóes das escolas de Brusque e entorno. 
Por consequência, pretende-se para 2016 aumentar de 5 para 10 escolas atendidas por semestre, pois além do aumento de solicitaçôes por parte das escolas, existe aumento da demanda de alunos voluntários para participar do projeto.

Desta maneira, conclui-se que hoje é indispensável às crianças, inseridas neste mundo globalizado, terem um espaço para o Lazer, evitando, desta forma, a monotonia, más companhias e o tédio. Porquanto, também é importante para os acadêmicos essa aproximação com a comunidade, processo quase impossível em suas rotinas de trabalho e estudo. Ao se relacionar com a comunidade, o acadêmico cria um olhar humano e crítico com relação às políticas públicas, direitos humanos e cultura.

Sugere-se à Instituição parcerias com outras organizaçóes, visando oferecer serviços de atendimento para os pais que prestigiam o local, como, por exemplo, enfermeiros para medir pressão cardíaca, educadores físicos para repassar exercícios de alongamento.

Por fim, há que seter em mente que investir em projetos sociais é qualificar a educação das Instituiçôes de Educação Superior. Deve-se colocar a educação no mapa político de todos os países, possibilitando o acesso para os ricos e para os pobres. A educação não é um luxo, mas, sim, uma aspiração. 


\section{Referências}

ACAFE. Memória. Disponível em: http://www.acafe.org.br/new/index.php. Acesso em: 06 jul. 2010.

ANDRADE, José Vicente de. Lazer - princípios, tipos e formas na vida e no trabalho. Belo Horizonte: Autêntica, 2001.

ANSARAH, Marília G. dos Reis (Org.). Turismo -Como aprender, como ensinar. São Paulo: SENAC, 2001.

BRASIL. Plano Nacional de Extensão Universitária. Edição atualizada. Brasília: Fórum de Pró-Reitores de Extensão das Universidades Públicas Brasileiras e SESu / MEC, 2001.

BRASIL. Constituição 1998. Texto Constitucional de 5 de outubro de 1998 com alterações adotadas pelas emendas constitucionais de revisão n. 1/1992 a 30/2000. Brasília: Ed. Atual, 2000.

CANO, Wilson. Raízes da concentração industrial em São Paulo. São Paulo: Hucitec, 1990.

GOMES, Cristina Marques. Pesquisa Científica em Lazer no Brasil - Bases Documentais e Teóricas. Dissertação (Mestrado) -ECA/USP, São Paulo, 2004.

GOULARTI FILHO, Alcides. Formação econômica de Santa Catarina. Florianópolis: Cidade Futura, 2002. 
GOVERNO DO ESTADO DE SANTA CATARINA. Santa Catarina. Disponível em: http://www.sc.gov.br. Acesso em: 14 dez. 2009.

INEP - INSTITUTO NACIONAL DE ESTUDOS E PESQUISAS EDUCACIONAIS. Educação Superior Brasileira.1991-2004. Brasília: Instituto Nacional de Estudos e Pesquisas Educacionais Anísio Teixeira, 2006.

MAMIGONIAN, Armen. Estudo geográfico das indústrias de Blumenau. Revista Brasileira de Geografia, v. 27, n. 3, p. 489-483, jul./set.1965.

MESQUITA FILHO, Alberto. Integração Ensino-Pesquisa-Extensão. Revista Integração, v. 9, p. 138-143, 1997. Disponível em:

http://ecientificocultural.com/ECC2/artigos/epe.htm. Acesso em: 17 set. 2015.

RAUD, CécileHèléne Jeanne. Indústria, território e meio ambiente no Brasil: perspectivas da industrialização descentralizada a partir da análise da experiência catarinense. Florianópolis: Ed. da UFSC; Blumenau: Ed. da FURB, 1999.

SOARES, Magda. Letramento: um tema em três gêneros. Belo Horizonte: Autêntica, 1998.

UNIFEBE. A Instituição. Disponível em: http://www.unifebe.edu.br/site/index.php/a-instituicao/ institucional. Acesso em: 02 jul. 2015. 